International

Medical Society

http://imedicalsociety.org

\title{
Popliteus Muscle. An Anatomical Study
}

Edna Rocío Buitrago1 2 , Iván Darío Quintero², Luis Ernesto Ballesteros²

\section{Abstract}

Background: The popliteus muscle fulfills a function of rotational stabilizer of the knee. Its particular shape and innervation pattern are the interest of anatomists and surgeons. The aim of this work was characterizing the anatomy and innervation of the popliteus muscle of knees from a sample of mestizo-raced population, predominant in Latin America.

Methods: This cross-sectional study was made in 23 knee segments 14 right knees and 9 left knees coming from 14 men and 9 women aged $67 \pm 22$ years.

Results: The popliteus muscle presented a scalene-like triangle shape and its medial base was covered by the superficial expansion of the semimembranosus tendon. The length of its base was $79,2 \pm 12,8 \mathrm{~mm}$ with a superior and inferior side that measured $58.0 \pm 7.4 \mathrm{~mm}$ and $101.7 \pm 11.7 \mathrm{~mm}$ respectively. The popliteus muscle innervation was supplied by the tibial nerve (TN) by the arising of two branches in 22 cases $(95.7 \%)$. The first branch arose proximal to the inter articular line and presented a length of $91.1 \mathrm{~mm}$. The second branch arose distally to the inter articular line with a length of $48.4 \pm 1.3 \mathrm{~mm}$. The third was observed in just one case (4.3\%) Its length was $108 \pm 1.1 \mathrm{~mm}$ and it arose distally to the inter articular line.

Conclusions: The morphological characteristics of the popliteus muscle and its innervation patterns found in our study differ from what was reported in previous studies. The presence of these findings can be considered during the planning of surgical procedures in the posterior aspect of the knee.
1 Division of Orthopedic Surgery, Department of Surgery, School of Medicine, Industrial University of Santander. Bucaramanga, Colombia.

2 Division of Human Anatomy, Department of Basic Sciences, School of Medicine, Industrial University of Santander. Bucaramanga, Colombia.

\section{Contact information:}

\section{Ivan Dario Quintero.}

Address: Division of Human Anatomy, Department of Basic Sciences, School of Medicine, Industrial University

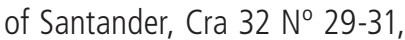
Bucaramanga, Colombia.

Tel: + (57) 3133028322

झ ivan.quintero@correo.uis.edu.co

\section{Keywords}

Knee; Popliteus Muscle; Popliteus Tendon; Posterolateral Corner. 


\section{Introduction}

The popliteus muscle (PM), located in the deep layer of the posterior compartment of the leg, is immediately proximal to the soleus line. Its function is still being studied. Some authors have pointed out that the PM has two proximal tendon-ligament origins, which were fused to form a muscular body in its distal insertion in the posterior surface of the tibia, the action of these fibers allow the knee to unlock while walking $[1,5,15,18]$. However, recent biochemical studies $[3,6,8]$ emphasize in the origin of PM is fundamentally tibial with its tendon insertion in the popliteal sulcus (PS) in the femur and its tendonligament complex in the structures that make up the posterolateral corner of the knee (PLC) fulfilling its function of a primary dynamic stabilizer of the external rotation between the tibia and the femur and of a secondary restrictor in posterior cruciate ligament $(\mathrm{PCL})$ injuries [7].

Initial anatomic studies $[1,5,15,18]$ made distinctly qualitative descriptions about PM morphology. Hwang [9], was the first one to describe quantitatively the dimensions of PM. Its scalenelike triangle shape configures a posterolateral acute angle over the junction with the PT, whereas its posteromedial angle becomes larger. Thereby the PM, short and thick, curses from the tibia to its insertion in the femur.

Furthermore, the PT and its conformation of $\mathrm{fi}$ ber bundles that interlace to confer stability to PLC of the knee, has reported a variability in its length prowling a range between 36-54.5 mm [11, 12]. This characteristic is involved in reparative and reconstructive processes from the structures that make up the PLC of the knee.

PM innervation is given by the tibial nerve (TN), however a full and detailed information about the morphometric characteristics of its innervation is still very limited, which are of big importance during surgical, esthetical and reconstructive procedures and in the leg and foot flexor musculature pain relief [2].
The aim of this study was to characterize the finding of anatomy of PM and its innervation, from the evaluation of fresh knees of a mestizo-raced population, predominant in Latin America.

\section{Materials and Methods}

This cross-sectional study was made in 23 knee segments 14 right knees and 9 left knees coming from 14 men and 9 women aged $67 \pm 22$ years. This knees coming from supracondylar amputations for ischemic pathologies as a part of the anatomopathological study developed in the Industrial University of Santander. For the sample selection, it was used as inclusion criteria: knees from adults that belonged to the mestizo race group (mixture between Europeans and Natives), without any anatomical alteration caused by the amputation, without surgery records, traumatisms or related pathologies. This investigation was approved by the Institutional Review Board (ethics committee).

For the PM exposure, a midline incision over the popliteal fossa that compromised skin, subcutaneous tissue and fascia was made. The plantaris muscle, the lateral gastrocnemius and the medial gastrocnemius were visualized releasing from their proximal insertions. The characteristics of the morphologic and morphometric expression of the PM and its insertion in the tibia and the femur, as well as the characteristics of the motor branches for the PM that arise from the TN having as reference the interarticular line of the knee (IAL) and its relation with the popliteal artery (PA) were determined.

The measurements were made with a digital gauge and the specimens were photographed with a digital camera. The findings were saved and underwent statistical analysis. The continuous variables were described with average and standard deviation, the nominal ones in percentages. The statistical variables were proved with a chi-squared test $\left(\chi^{2}\right)$, student's T-test and the test of acceptance 
of an alpha error until $5 \%$. A result of $p<0.05$ was considered significant.

\section{Results}

Popliteus Muscle origin was located in the posterior surface of the tibia, immediately distal to the interarticular line (IAL). PM was presented elongated, thin and shaped like a scalene triangle; its medial base was covered by the superficial expansion of the semimembranosus tendon. The length of its base was $79.2 \pm 12.8 \mathrm{~mm}$ with a superior and inferior side that measured $58.0 \pm 7.4 \mathrm{~mm}$ and $101.7 \pm 11.7 \mathrm{~mm}$ respectively, without presenting statistically significant differences related to its side of presentation or gender $(p=0.18)$. From its muscular insertion in the tibia, the popliteus tendon (PT) went from medial to lateral following an ascendant trajectory to its femoral insertion. The PT presented a length of $38.3 \pm 3.9 \mathrm{~mm}$ with a thickness of $3.1 \pm 0.5 \mathrm{~mm}$ in the middle of its course, without presenting statistically significant differences related to its side of presentation ( $p=0.21$ ) (Figure 1. A).

Figure 1: A. Right knee, lateral side view, femoral attachmentof the popliteal muscle.

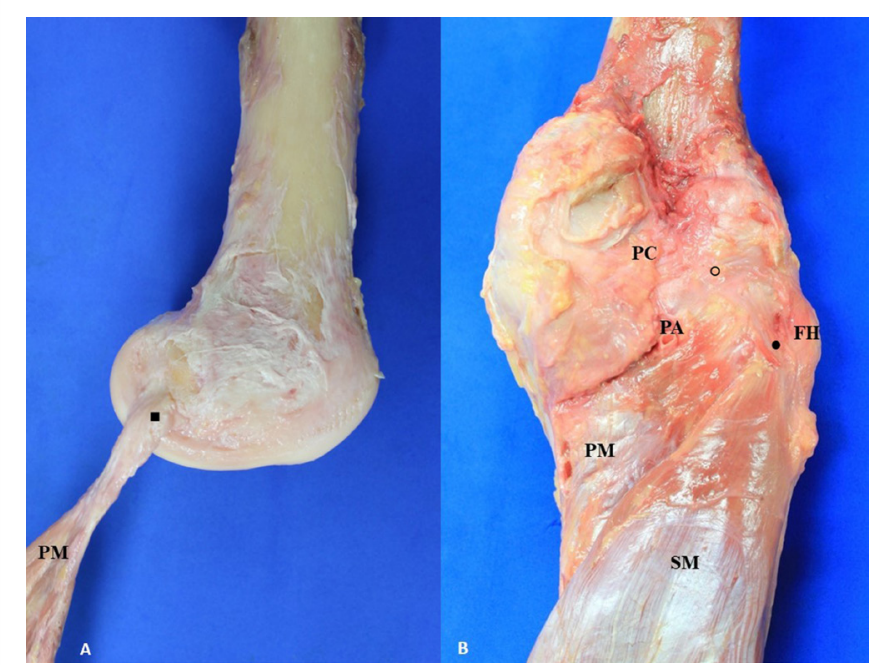

a: popliteus tendon; PM: popliteus muscle. B. Right knee posterior view, attachment of the poplíteus muscle; o: capsular and meniscal attachments; -: popliteofibular ligament; PC: posterior articular capsule; PA: popliteal artery PM: popliteus muscle; FH: fibular head; SM: soleus Muscle.
At the level of the PM myotendinous junction, ligamentous bands oriented towards the head of the fibula (Popliteal-fibular ligament), the posterior horn of the lateral meniscus (Popliteal-meniscal ligament) and the joint capsule arose; those characteristics were observed in the sample. (Fi-

\section{gure 1. B).}

Popliteus muscle innervation was supplied by the tibial nerve (TN) by the arising of two branches in 22 cases (95.7\%) and three branches in one case (4.3\%). The first branch arose proximal $(50.3 \pm 1.5 \mathrm{~mm})$ to the $\mathrm{IAL}$ and presented a length of $91.1 \mathrm{~mm}$ (Figure 2.A). This branch was divided in 4 segments according to its anatomic relation with the PA: The first segment $\left(\mathrm{N}_{1}\right.$ or pre-vascular) with a length of $49.9 \pm 5.8 \mathrm{~mm}$, was located lateral to PA. The second segment $\left(\mathrm{N}_{2}\right.$ or vascular) adopted a profound trajectory to PA and measured $17.8 \pm 3.7 \mathrm{~mm}$. The third segment $\left(\mathrm{N}_{3}\right.$ or post-vascular) of this branch, with a length of $33.4 \pm 30.8 \mathrm{~mm}$ followed a descendant and medial trajectory in relation to the PA and was accompanied by the middle genicular vessels and they all reached the superior border of the PM. Finally, this nervous branch cursed sub facially over the posterior surface of the PM, presenting in this distal segment $\left(\mathrm{N}_{4}\right.$ or sub facial) a length of $19.5 \pm 4.4 \mathrm{~mm}$. The motor point of the branch form TN was located $35.2 \pm 0.5 \mathrm{~mm}$ from the IAL.

The second branch for the PM arose from TN distally to the IAL $(27.52 \pm 0.7 \mathrm{~mm})$ with a length of $48.4 \pm 1.3 \mathrm{~mm}$; it was presented as a common trunk with the branch for the posterior tibialis muscle in 20 cases (87\%). From its arising, it cursed with a lateral trajectory to the TN and descended over the posterior surface of the PM until it reached the middle segment of its inferior border and thus giving this muscle its innervation along with the posterior tibialis muscle (Figure 2.B). In two specimens $(8.7 \%)$ a common trunk with branches for the PM and for the soleus muscle was observed. Its motor point was located $47 \pm 1.3 \mathrm{~mm}$ distal to the IAL. 
Figure 2: A. Right knee posterior view, first branch to popliteus muscle.

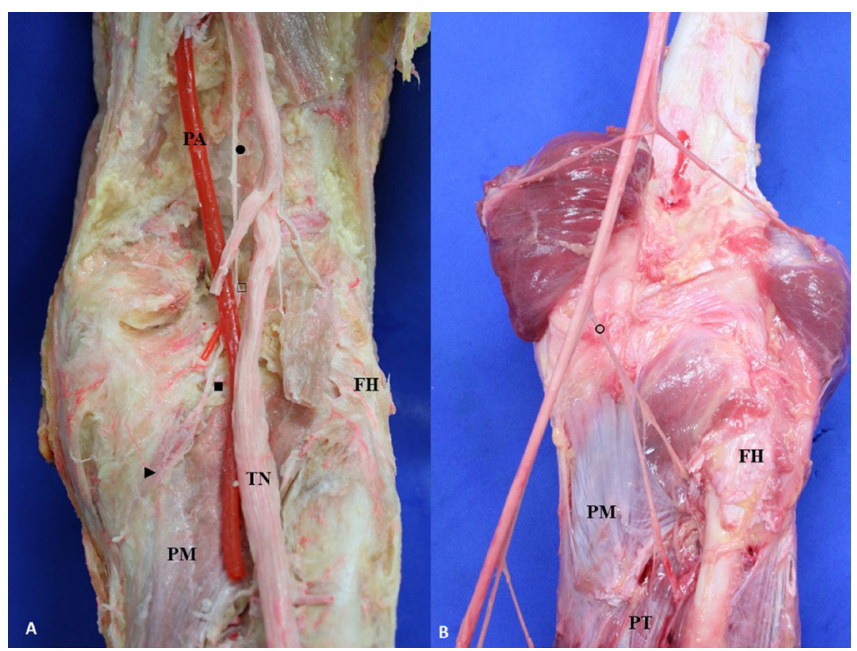

-: pre-vascular segment N1; $\square$ : vascular segment N2; $\mathbf{m}$ : post-vascular segment N3; : sub-fascial segment N4; PA: popliteal artery; TN: Tibial Nerve; PM: popliteus muscle; FH: fibular head. B. Right knee posterolateral view, second branch to popliteus muscle; o: common trunk to popliteus and tibialis posterior; TN: Tibial Nerve; PM: popliteus muscle; FH: fibular head; TP: tibialis

The third branch for the PM was observed in just one case $(4.3 \%)$ arising from the TN in a common trunk with branches for the plantaris, soleus and posterior tibialis muscles. Its length was $108 \pm 1.1 \mathrm{~mm}$ and its motor point was located $22.4 \pm 0.8 \mathrm{~mm}$ distal to the IAL.

\section{Discussion}

PM is the most proximal muscle located in the deep layer of the posterior surface of the leg. Its triangular shape allows it to adopt an oblique trajectory having contact with the tibia and the femur to contribute in the stabilization of the knee $[6,7]$. The PM dimensions that were found in our study allowed its qualitative characterizing as a triangular, elongated and thin muscle, similar to what was reported in initial anatomical studies [1, 8]. Meanwhile, Hwang [9] in his study about the PM shape and innervation developed in Korean cadaveric specimens, describes the PM as a short and thick muscle. It is only in our series and Hwang's studies that a morphometric description of the PM dimensions is made. Previous reports $[1,8,14,15]$ made only a qualitative description about its morphology finding elongated and thin shape for the PM as described in our study. This divergence in the PM morphological characterization could be explained due to the variation in height of the studied individuals, proper of each demographic group.

PT length, width and thickness found in our work are located in a medial range to what was reported in eastern countries studies [11, 20]. In the mentioned works, the PT presented a length between $36.0 \mathrm{~mm}-40.4 \mathrm{~mm}$, with a PT width of $6.3 \mathrm{~mm}-10.1 \mathrm{~mm}$ and a thickness in a range of 2.4 $\mathrm{mm}-3.6 \mathrm{~mm}$. On the other hand, the PT length found in our series is smaller than the one reported in the American population. Fineberg et al. [4] and LaPrade et al. [12] reported the PT length of $42 \mathrm{~mm}$ - $54.4 \mathrm{~mm}$, establishing length ranges for the PT way above our findings (Table 1). This morphological feature can be possibly explained by the fact that Americans have a larger size relative to the Latin American population and by the differences in measurement criteria of the PT length among different authors [4, 12, 13].

Table 1. Morphometric characteristics of popliteus tendon in different population groups.

\begin{tabular}{|c|c|c|c|c|c|}
\hline \multirow{2}{*}{ Author } & \multirow{2}{*}{ Country } & \multirow{2}{*}{$\begin{array}{c}\text { Sample } \\
\text { size }\end{array}$} & \multirow{2}{*}{$\begin{array}{c}\text { Lenght } \\
\mathrm{mm}\end{array}$} & \multirow{2}{*}{$\begin{array}{c}\text { Width } \\
\mathrm{mm}\end{array}$} & \multirow{2}{*}{$\begin{array}{c}\text { Thickness } \\
\mathrm{mm}\end{array}$} \\
\hline & & & & & \\
\hline $\begin{array}{l}\text { Fineberg } \\
{[4]}\end{array}$ & USA & 5 & 42 & - & - \\
\hline $\begin{array}{l}\text { Ishigooka } \\
\text { [10] }\end{array}$ & Japan & 78 & 40.4 & 7.5 & 3.6 \\
\hline Jung [11] & Korea & 18 & 36 & 8 & - \\
\hline $\begin{array}{l}\text { LaPrade } \\
\text { [13] }\end{array}$ & USA & 10 & 54.5 & - & - \\
\hline $\begin{array}{l}\text { Wadia } \\
\text { [19] }\end{array}$ & India & 25 & - & 10.1 & - \\
\hline Zeng [20] & China & 81 & $38.2 \pm 5.2$ & $6.3 \pm 1.1$ & $2.4 \pm 0.9$ \\
\hline $\begin{array}{l}\text { Present } \\
\text { study }\end{array}$ & Colombia & 23 & $38.3 \pm 3.9$ & $8.9 \pm 1.6$ & $3.1 \pm 0.5$ \\
\hline
\end{tabular}


PM biomechanical functions have been established according to the direction of the vector formed between its origin and insertion bone structure surfaces. The first studies that reported the PM anatomy, pointed out two tendon-ligament proximal origins, one in the head of the fibula and the other one in the lateral condyle of the femur; and its insertion in a muscular body over the posterior surface of the tibia. It is showed that the PM serves as an anchor to unlock the knee during walking having a function of inverse contraction [1, 5, 8, 15]. On the other hand, various recent studies have determined the PM implication as a primary dynamic stabilizer of the external rotation between the tibia and the femur taking into consideration its distal origin and proximal insertion [7, 16, 17].

About the PM innervation, Hwang [9] found a branch coming from the TN that was always proximal to the IAL and it was the only branch for the PM. In our study up to 3 branches were found innervating the PM. The first branch, always proximal as Hwang [9] reported, was divided into four segments with the PA. Besides the importance of the PM morphological characteristics mentioned, it is worth mentioning that the knowledge of the PM innervation must be considered in the infiltrative processes made for pain relief in certain patients with leg and feet flexor spasticity secondary to stroke [2]. If the location of the PM branches and its relation with the branches for other muscles of the posterior layer are not considered, iatrogenic effects could be generated and compromise the knee's posterolateral stability in patients without any records of direct or rotation trauma over the knee.

The morphological characteristics of the popliteus muscle and its innervation patterns found in our study differ from what was reported in previous studies. Our study is innovative since it does a detailed description of the innervation patterns for the popliteus muscle and can be used as reference for its planning, development and execution surgical neurotomy techniques for a reduction of the muscular mass as well as for the treatment of spastisty in the posterior aspect of the leg also the presence of these findings can be considered during the planning of the surgical approach of the medial and lateral tibial plateau in the posterior aspect of the knee.

\section{Conflict of interests}

The authors declare that there was no conflict of interests in conducting this study.

\section{Declaration}

The authors Buitrago ER, Quintero ID and Ballesteros LE contributed equally to the work.

\section{References}

1. Amonoo-Kuofi HS. Morphology of muscle spindles in the human popliteus muscle. Evidence of a possible monitoring role of the popliteus muscle in the locked knee joint. Acta Anat (Basel). 1989; 134(1):48-53. Available from: www.ncbi.nlm.nih. gov/pubmed/2524148

2. Baroncini M, Baïz H, Wavreille G, Demondion X, Maurage CA, Buisset N, Blond S, Kim HJ, Fontaine C. Anatomical bases of tibial neurotomy for treatment of spastic foot. Surg Radiol Anat. 2008 Aug; 30(6):503-8. Available from: www.ncbi.nlm.nih.gov/ pubmed/18480959

3. Feipel $V$, Simonnet $M L$, Rooze M. The proximal attachments of the popliteus muscle: a quantitative study and clinical significance. Surg Radiol Anat. 2003; 25(1):58-63. Available from: www.ncbi.nlm.nih.gov/pubmed/12677465

4. Fineberg MS, Duquin TR, Axelrod JR Arthroscopic visualization of the popliteus tendon. Arthroscopy. 2008 Feb; 24(2):174-7. Available from: www.ncbi.nlm.nih.gov/pubmed/18237701

5. Fuss FK. An analysis of the popliteus muscle in man, dog, and pig with a reconsideration of the general problems of muscle function. Anat Rec. 1989; 225(3):251-6. Available from: www. ncbi.nlm.nih.gov/pubmed/2817443

6. Harley JD. An anatomic-arthrographic study of the relationships of the lateral meniscus and the popliteus tendon. AJR Am J Roentgenol. 1977; 128(2):181-7 Available from: www.ncbi.nlm. nih.gov/pubmed/401598

7. Harner CD, Höher J, Vogrin TM, Carlin GJ, Woo SL. The effects of a popliteus muscle load on in situ forces in the posterior cruciate ligament and on knee kinematics. A human cadaveric study. Am J Sports Med. 1998; 26(5):669-73. Available from: www.ncbi.nlm.nih.gov/pubmed/9784814 
8. Higgins H. The Popliteus Muscle. J Anat Physiol. 1895; 29(Pt 4):569-73. Available from: www.ncbi.nlm.nih.gov/ pubmed/17232158

9. Hwang K, Lee KM, Han SH, Kim SG. Shape and innervation of popliteus muscle. Anat Cell Biol. 2010; 43(2):165-8. Available from: www.ncbi.nlm.nih.gov/pubmed/21189998

10. Ishigooka H, Sugihara T, Shimizu K, Aoki H, Hirata K. Anatomical study of the popliteofibular ligament and surrounding structures. J Orthop Sci. 2004; 9(1):51-8. Available from: www.ncbi.nlm. nih.gov/pubmed/14767705

11. Jung GH, Kim JD, Kim H. Location and classification of popliteus tendon's origin: cadaveric study. Arch Orthop Trauma Surg. 2010; 130(8):1027-32. Available from: www.ncbi.nlm.nih.gov/ pubmed/20521059

12. LaPrade RF, Wozniczka JK, Stellmaker MP, Wijdicks CA. Analysis of the static function of the popliteus tendon and evaluation of an anatomic reconstruction: the "fifth ligament" of the knee. Am J Sports Med. 2010; 38(3):543-9. Available from: www. ncbi.nlm.nih.gov/pubmed/20042547

13. LaPrade RF, Ly TV, Wentorf FA, Engebretsen L. The posterolateral attachments of the knee: a qualitative and quantitative morphologic analysis of the fibular collateral ligament, popliteus tendon, popliteofibular ligament, and lateral gastrocnemius tendon. Am J Sports Med. 200; 31(6):854-60. Available from: www.ncbi.nlm.nih.gov/pubmed/14623649

14. Mann RA, Hagy JL. The popliteus muscle. J Bone Joint Surg Am. 1977; 59(7):924-7. Available from: www.ncbi.nlm.nih.gov/ pubmed/908724

15. Paraskevas G, Papaziogas B, Kitsoulis P, Spanidou S. A study on the morphology of the popliteus muscle and arcuate popliteal ligament. Folia Morphol. 2006; 65(4):381-4. Available from: www.ncbi.nlm.nih.gov/pubmed/17171619

16. Peterson L, Pitman MI, Gold J. The active pivot shift: the role of the popliteus muscle. Am J Sports Med. 1984; 12(4):313-7. Available from: www.ncbi.n/m.nih.gov/pubmed/6476190
17. Schinhan M, Bijak M, Unger $E$, Nau T. Electromyographic study of the popliteus muscle in the dynamic stabilization of the posterolateral corner structures of the knee. Am J Sports Med. 2011; 39(1):173-9. Available from: www.ncbi.nlm.nih.gov/ pubmed/20807859

18. Taylor G, Bonney V. On the Homology and Morphology of the Popliteus Muscle: A Contribution to Comparative Myology. J Anat Physiol. 1905; 40(Pt 1):34-50. Available from: www.ncbi. nlm.nih.gov/pubmed/17232661

19. Wadia FD, Pimple M, Gajjar SM, Narvekar AD. An anatomic study of the popliteofibular ligament. Int Orthop. 2003; 27(3):172-4. Available from: www.ncbi.nlm.nih.gov/pubmed/12799761

20. Zeng SX, Wu GS, Dang RS, Dong XL, Li HH, Wang JF, Liu J, Wang D, Huang HL, Guo XD. Anatomic study of popliteus complex of the knee in a Chinese population. Anat Sci Int. 2011 Dec; 86(4):213-8. Available from: www.ncbi.nlm.nih.gov/ pubmed/21837463
Publish in International Archives of Medicine

International Archives of Medicine is an open access journal publishing articles encompassing all aspects of medical science and clinical practice. IAM is considered a megajournal with independent sections on all areas of medicine. IAM is a really international journal with authors and board members from all around the world. The journal is widely indexed and classified Q2 in category Medicine. 